\title{
Headspace GC-SCD monitoring of low volatile sulfur compounds during fermentation and in wine*
}

\author{
D. Rauhut ${ }^{1}$, H. Kürbel ${ }^{1}$, K. MacNamara ${ }^{2}$ and M. Grossmann ${ }^{1}$ \\ ${ }^{1}$ Fachgebiet Mikrobiologie und Biochemie, Forschungsanstalt Geisenheim, \\ Von-Lade-Straße 1, D-65366 Geisenheim, Germany \\ ${ }^{2}$ Irish Distillers Limited, Bow Street Distillery, Smithfield, Dublin 7, Ireland
}

\begin{abstract}
A rapid and reliable method for the determination and quantification of volatile sulfur compounds in wine is reported. The analysis was carried out with an automatic headspace injection sampler combined with a cooled injection system and coupled with a gas chromatograph and a sulfur chemiluminescence (GC-SCD) detector. The calibration curves were calculated in a wine with a very low amount of sulfur compounds. As internal standard ethyl methyl sulfide was used. In dependence on the Scompound the detection limit was in the range of 0.1 to $3 \mu \mathrm{g} / \mathrm{L}$. A linear response was obtained up to a concentration of about $100 \mu \mathrm{g} / \mathrm{L}$ with an average correlation coefficient of 0.998 . Major advantages are the small sample volume ( $3 \mathrm{~mL})$, the high repeatability or reproducibility and a short total analysis time.
\end{abstract}

Key words. Low volatile sulfur compounds in wine - automatic headspace technique - sulfur chemiluminescence detector.

\section{Introduction}

Very low levels of sulfur (S)-compounds give wines their distinctive aroma, but in higher concentrations they can create unappealing flavours. A rapid and reproducible detection of S-compounds in wine becomes more and more important for quality control and research analysis. Therefore a multi-purpose-sampler, designed for liquid large volume, gaseous and headspace samples was tested for its suitability in the headspace analysis of low volatile S-compounds in wine and during fermentation.

\section{Experimental}

An automatic headspace sampling system (Multi Purpose Sampler used as Headspace-Sampler, Gerstel GmbH, Mülheim a. R., Germany) with a volume, temperature and speed controlled $1000 \mu \mathrm{L}$ gas tight syringe was combined with a temperature controlled cooled injection system (CIS-

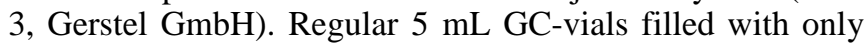
$3 \mathrm{~mL}$ sample were used as headspace sampling vials. The wine samples are stored at $4{ }^{\circ} \mathrm{C}$ before sample preparation. A high advantage of this method is the low sample volume. Each sample is heated for the same period of time at the same temperature in the preheating station (45 min). After preheating the sample is injected into the cooled CIS-3 (Gerstel) for cold trapping, focussing and enrichment and after heating up to the desired temperature transferred to the capillary column in either split or splitless mode. The most suitable column for the detection of low volatile S-compounds in wine seems to be a SPB-1-Sulfur (Supelco INC., Bellefonte PA, USA) which was also used in this study. The samples were investigated on a Siemens Sichromat 2 (Siemens, Karlsruhe, Germany) fitted with a SCD 350 B (Sievers Instrument, Boulder, Colorado,USA) sulfur chemiluminescence detector. The SCD 350 is coupled to a flame ionization detector (FID). The SCD is a very sensitive and selective detector for sulfur compounds in different kinds of beverages. It gives a linear response over a wide concentration range and there is no problem of hydrocarbon quenching $[1,3,4,6]$.

The liner of the CIS-3 was filled with a porous polymer to increase the enrichment capacity. Sensitivity of the system was enhanced by the addition of sodium chloride to the sample. A concentration of $0.8 \mathrm{~g} \mathrm{NaCl} / 3 \mathrm{~mL}$ sample $(0.27 \mathrm{~g} / \mathrm{mL})$ enhanced the response of the sulfur compounds about 80 to 100 per cent.

The first studies were carried out with hydrogen as carrier gas. Afterwards helium (He) was used, because in future the GC Sichromat 2 will be coupled with a mass spectrometer system.

Ethyl methyl sulfide (EMS) was used as internal standard $(30 \mu \mathrm{g} / \mathrm{L}$ EMS $)$.

\section{Analysis conditions}

\section{- Headspace Single Injection (HSI)}

Injection: total volume $5000 \mu \mathrm{L}$ (5 times $1000 \mu \mathrm{L}$ of each sample).

Temperature: syringe $60{ }^{\circ} \mathrm{C}$ and preheating station $60{ }^{\circ} \mathrm{C}$. Preheating time: $45 \mathrm{~min}$.

\section{- Cooled injection System CIS-3}

Liner: filled with $25 \mathrm{mg}$ Porapak Q 80/100 mesh (WGA, Düsseldorf, Germany.

Temperature program: $-60{ }^{\circ} \mathrm{C}, 12{ }^{\circ} \mathrm{C} / \mathrm{s} \boldsymbol{\lambda} 180{ }^{\circ} \mathrm{C}$ for $8 \mathrm{~min}$. Split flow through the liner: $50 \mathrm{~mL} / \mathrm{min}$.

Splitless time: $8 \mathrm{~min}$. 


\section{- Gas chromatograph}

Column: SPB-1 Sulfur.

(30 m $\times 0.32 \mathrm{~mm}$ I. D., $4 \mu \mathrm{m}$ film thickness, Supelco).

Temperatures: $35{ }^{\circ} \mathrm{C}$ for $5 \mathrm{~min}, 10{ }^{\circ} \mathrm{C} / \mathrm{min} \boldsymbol{\lambda} 180{ }^{\circ} \mathrm{C}$ for

8 min.

Linear gas velocity for hydrogen was $40 \mathrm{~cm} / \mathrm{s}$ at $60^{\circ} \mathrm{C}$.

Linear gas velocity for helium was $22 \mathrm{~cm} / \mathrm{s}$ at $60{ }^{\circ} \mathrm{C}$.

Split: 1:20.

\section{- Sulfur chemiluminescence detector:}

Detector temperature of the FID: $240{ }^{\circ} \mathrm{C}$.

Gas flow conditions: $250 \mathrm{~mL} / \mathrm{min} \mathrm{H}_{2} .375 \mathrm{~mL} / \mathrm{min}$ air. $27 \mathrm{~mL} / \mathrm{min}$ air for make-up gas.

\section{Results and discussion}

The analytical method can be practised for detection and quantification of volatile sulfur compounds in wine like hydrogen sulfide $\left(\mathrm{H}_{2} \mathrm{~S}\right)$, methanethiol $(\mathrm{MeSH})$, carbon disulfide $\left(\mathrm{CS}_{2}\right)$, ethanethiol (EtSH), dimethyl sulfide (DMS), thioacetic acid methyl ester (MeSAc), thioacetic acid ethyl ester (EtSAc), dimethyl disulfide (DMDS), ethyl methyl disulfide (MeSSEt) and diethyl disulfide (DEDS). An oxidation of the mercaptanes to the disulfides during sample preparation could be eliminated by the addition of an antioxidant like $4 \mathrm{mg} / \mathrm{L}$ 2,6-di-tert-butyl-4-methyl-phenol. EDTA (ethylenediamine tetraacetic acid) can be used to avoid the interference with metals.

The calibration curves were calculated in wine and in synthetic must- and wine-like media. In dependence on the $\mathrm{S}$-compound the detection limit was in the range of 0.1 to $3 \mu \mathrm{g} / \mathrm{L}$. A linear response was obtained up to a concentration of about $100 \mu \mathrm{g} / \mathrm{L}$ with an average correlation coefficient of 0.998 . The calibration graphs for $\mathrm{MeSH}$ $(r=0.991)$ and for EtSAc $(r=0.999)$ are shown in figures 1 and 2 (A. is used as abbreviation for area).

The repeatability and reproducibility error is between 5 $10 \%$. The calibration in wine was carried out by the addition of the S-compounds in different quantities to a wine with a low content of the S-substances and without addition of sulfur dioxide $\left(\mathrm{SO}_{2}\right)$.

Sulfur dioxide can be added to wine as an antioxidant and antimicrobial agent. Commercial wines contain up to $50 \mathrm{mg} / \mathrm{L}$ free $\mathrm{SO}_{2}$ or even more. High concentrations of $\mathrm{SO}_{2}$ interfere with the detection of the other volatile S-com-

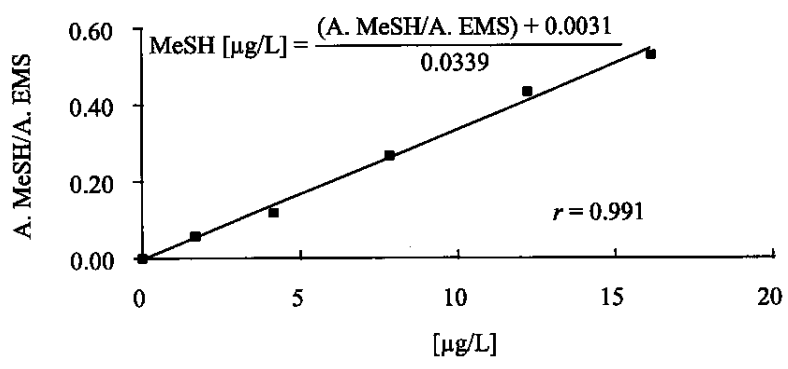

Fig. 1. Calibration graph for dimethyl sulfide (MeSH) from wine. Each point represents the average value of five independent measurements.

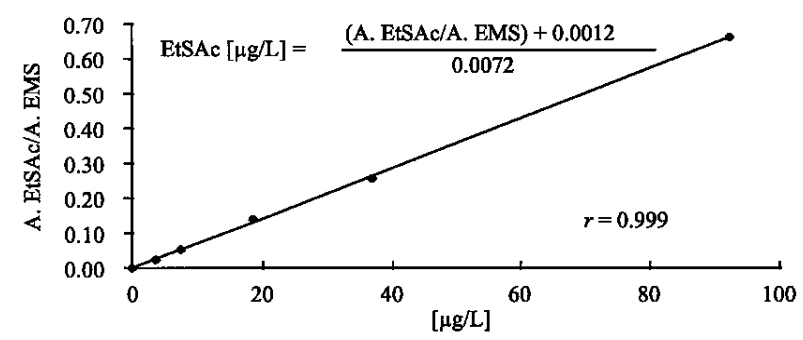

Fig. 2. Calibration graph for thioacetic acid ethyl ester (EtSAc) from wine. Each point represents the average value of five independent measurements.

pounds, which occur in wine in significant lower concentrations. $\mathrm{SO}_{2}$ reacts with carbonyl compounds. The reaction depends upon $\mathrm{pH}$, temperature and concentration of reactants [2]. Therefore ethanal, propanal, pyruvic acid and 2ketoglutaric acid (also in combination) were given to the wines to eliminate free $\mathrm{SO}_{2}$.

The best results were obtained with the addition of propanal. In most cases $500 \mathrm{mg} / \mathrm{L}$ of propanal seem to be enough to bind free $\mathrm{SO}_{2}$ in wines (see Fig. 3). The influence of propanal on the quantitative measurement of the S-compounds was tested in wines with and without free $\mathrm{SO}_{2}$, especially with different amounts of $\mathrm{H}_{2} \mathrm{~S}$ and EtSH. No artefact production could be observed during the normal analysis time even if $1000 \mathrm{mg} / \mathrm{L}$ propanal were added to the samples. There was also no change in the repeatability.

Known amounts of the S-compounds $(n=5$ for each concentration) under investigation are added to different wines to determine the recoveries. For all S-substances the recovery was in the range of $85-110 \%$.The standard deviations of the various amounts of the investigated S-substances were very low ( $s= \pm 1.3- \pm 2.1 \mu \mathrm{g} / \mathrm{L} \mathrm{S}$-substance). This is a difference in the measurements about $\pm 5-10 \%$.

Figure 4 shows a chromatogram of a wine with a sulfurous off-flavour. In this case elemental sulfur residues in the must were the cause for the production of increased amounts of thioacetic acid esters and mercaptanes during fermentation [5].

Table I gives an overview about the different concentrations of low volatile S-substances in wines with and without sulfurous off-flavour from different wine growing countries.

Methanethiol was detected in every wine. Concentrations of more than $1.5 \mu \mathrm{g} / \mathrm{L}$ of methanethiol seem to be responsible for the occurring of off-flavours in wine in connection with a significant increase of other S-components with higher boiling points [5]. The detected levels of $\mathrm{H}_{2} \mathrm{~S}$ are far away from the threshold value which normally is in the range of 50 to $80 \mu \mathrm{g} / \mathrm{L}$. Therefore $\mathrm{H}_{2} \mathrm{~S}$ cannot be the reason for the off-flavour in these wines.

\section{Conclusion}

Headspace sample injection combined with a cooled injection system and coupled with a GC-SCD is an attractive alternative to classical static or dynamic headspace methods for the detection and quantification of low molecular sulfur compounds in different beverages. Furthermore the injection 

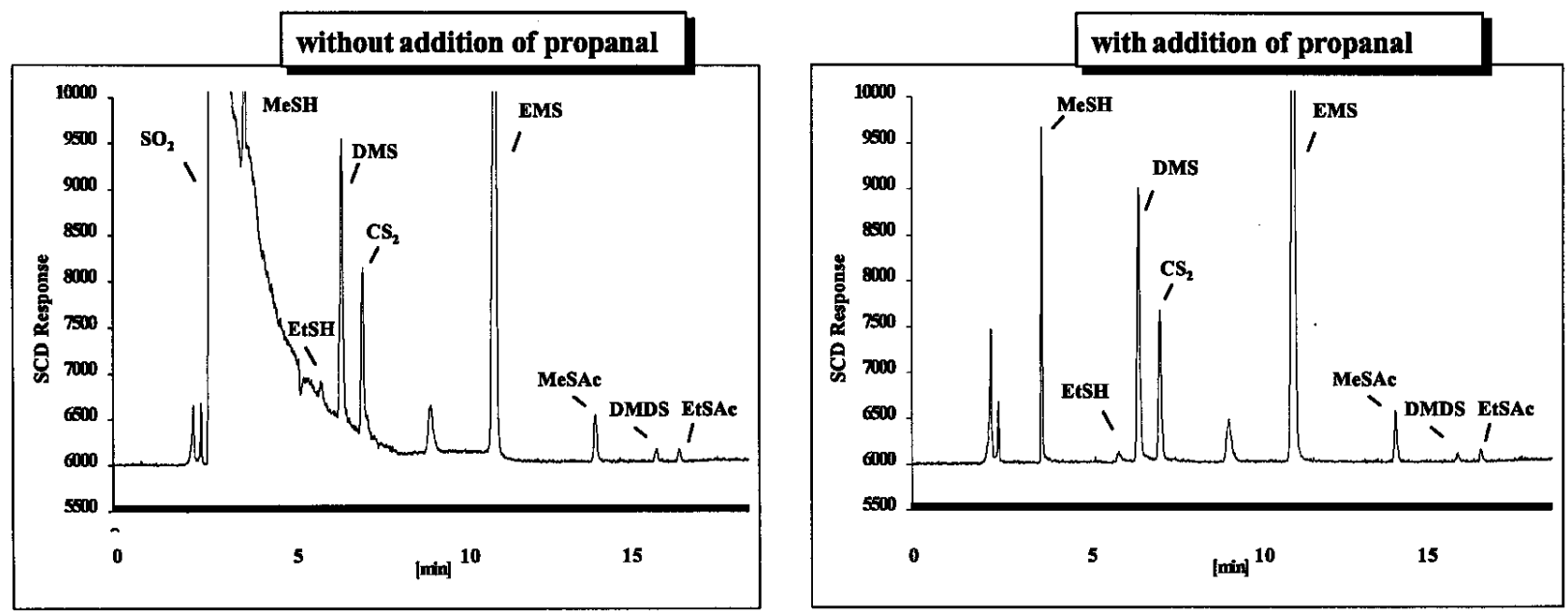

Fig. 3. Chromatograms of a wine with off-flavour before (A) and after (B) addition of $500 \mathrm{mg} / \mathrm{L}$ propanal by HSI-GC-SCD-Analysis(GCcolumn: SPB-1-sulfur, carrier gas: $\mathrm{He}$ ).

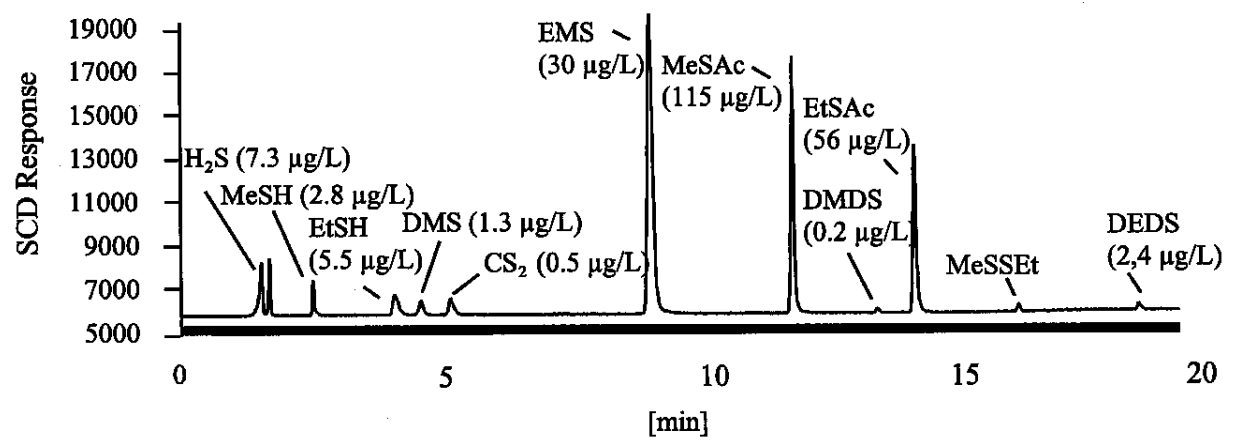

Fig. 4. Chromatogram of a young wine with a sulfur off-flavour by Headspace GC-SCD Analysis (GC-column: SPB-1-sulfur, carrier gas: $\mathrm{H}_{2}$ ).

Table I. Concentrations of low volatile sulfur compounds in different wines.

\begin{tabular}{|c|c|c|c|c|c|c|c|c|c|c|c|}
\hline wine sample & $\begin{array}{l}H_{2} S \\
\mu g / L\end{array}$ & $\begin{array}{c}M e S H \\
\mu g / L\end{array}$ & $\begin{array}{l}E t S H \\
\mu g / L\end{array}$ & $\begin{array}{l}D M S \\
\mu g / L\end{array}$ & $\begin{array}{c}C S_{2} \\
\mu g / L\end{array}$ & $\begin{array}{c}M e S A c \\
\mu g / L\end{array}$ & $\begin{array}{c}D M D S \\
\mu g / L\end{array}$ & $\begin{array}{c}E t S A c \\
\mu g / L\end{array}$ & $\begin{array}{c}M e S S E t \\
\mu g / L^{I)}\end{array}$ & $\begin{array}{c}D E D S \\
\mu g / L\end{array}$ & $\begin{array}{c}\text { Off- } \\
\text { Flavour }\end{array}$ \\
\hline 1985 Riesling & n. d. ${ }^{2)}$ & 2.8 & n. d. & 41.7 & 1.6 & n. d. & 2.4 & n. d. & n. d. & n. d. & yes \\
\hline 1985 Riesling & traces & 4.8 & n. d. & 52.7 & 1.9 & n. d. & 2.3 & n. d. & n. d. & n. d. & yes \\
\hline 1989 Müller-Thurgau & 3.9 & 0.5 & traces & 28.5 & 2.2 & traces & Traces & n. d. & n. $d$. & n. d. & no \\
\hline 1991 Riesling & 1.6 & 1.2 & n. d. & 18.2 & 3.0 & n. d. & Traces & n. d. & n. d. & n. d. & no \\
\hline 1992 Pinot noir & 3.2 & 7.1 & n. d. & 45.5 & 1.2 & traces & Traces & n. d. & n. d. & n. $d$. & yes \\
\hline 1992 Riesling & 8.2 & 4.5 & traces & 22.9 & 1.3 & n. d. & n. d. & n. d. & n. d. & traces & yes \\
\hline 1993 Scheur ebe & n. d. & 1.0 & traces & 9.2 & 4.9 & 3.1 & Traces & traces & n. d. & n. d. & no \\
\hline 1994 Riesling & traces & 1.6 & n. d. & 11.7 & 2.4 & 10.2 & Traces & traces & n. d. & traces & yes \\
\hline 1995 Riesling & 2.9 & 0.6 & n. d. & 10.1 & 1.1 & traces & n. d. & n. d. & n. d. & n. d. & no \\
\hline 1996 Chardonnay & 6.5 & 0.5 & traces & 25.0 & 1.1 & n. d. & n. d. & n. d. & n. d. & n. d. & no \\
\hline 1996 red wine & 2.6 & 0.5 & traces & 9.1 & 1.8 & traces & n. d. & n. d. & n. d. & n. d. & no \\
\hline 1996 Müller-Thurgau & 4.1 & 4.4 & n. d. & 1.6 & 1.4 & traces & 1.7 & n. d. & n. d. & n. $d$. & yes \\
\hline 1996 Muscat & 4.1 & 3.1 & traces & 2.9 & 2.7 & 12.3 & Traces & traces & n. d. & n. d. & yes \\
\hline Pinot noir & 7.3 & 2.8 & 5.5 & 1.3 & 0.5 & 115.0 & 0.2 & 56.0 & 3.0 & 2.4 & yes \\
\hline 1996 Riesling & 2.2 & 1.0 & n. d. & 9.5 & 3.6 & n. d. & n. d. & n. d. & n. d. & n. d. & no \\
\hline
\end{tabular}

${ }^{1)}$ calculated with the calibration graph of diethyl disulfide (DEDS), ${ }^{2)}$ not detected. 
compounds in different beverages. Furthermore the injection operation can be automated.

\section{References}

1. Burmeister, M. S.; Drummond, C. J.; Pfisterer, E. A.; Hysert, D. W.; Sin, Y. O.; Sime, K. J.; Hawthorne, D. B. Measurement of volatile sulfur compounds in beer using gas chromatography with a sulfur chemiluminescence detector $J$. Am. Soc. Brew. Chemists 1992, 50, 53-58.

2. Burroughs, L. F.; Sparks, A. H. Sulphite-binding power of wines and ciders II. Theoretical consideration and calculation of sulphite-binding equilibria J. Sci. Food Agric. 1973, 24, 199-206.

3. Eckert-Tilotta, S. E.; Hawthorne, St. B.; Miller, D. J. Comparison of commercially available atomic emission and chemiluminescence detectors for sulfur-selective gas chromatographic detection J. Chromatogr. 1992, 591, 313-323.

4. Nedjma, M.; Maujean, A. Improved chromatographic analysis of volatile sulfur compounds by the static headspace technique on water-alcohol solutions and brandies with chemiluminescence detection J. Chromatogr. A 1995, 704, 495-502.

5. Rauhut, D. Qualitätsmindernde schwefelhaltige Stoffe im Wein, Vorkommen, Bildung, Beseitigung, Dissertation Universität Gießen, Hrsg. Gesellschaft zur Förderung der Forschungsanstalt Geisenheim, Band 24, 1996.

6. Rauhut, D.; Kürbel, H. Analysis of volatile sulfur compounds in wine using gas chromatography with a sulfur chemiluminescence detector In: Sixteenth International Symposium on Capillary Chromatography, Riva del Garda, Italy, September 27-30, Volume I, Hrsg.: Sandra, P. and Devos, G. Eds., Hüthig Verlag: Heidelberg, 1994; pp 732-741. 